\title{
Editorial for the special issue "FOA-12" in "adsorption" by the guest editor Andreas Seidel-Morgenstern
}

\author{
Andreas Seidel-Morgenstern ${ }^{1}$
}

Published online: 18 February 2017

(C) Springer Science+Business Media New York 2017

This special issue of adsorption is devoted to present selected papers from the 12th International Conference on the Fundamentals of Adsorption (FOA12) which was held in Friedrichshafen at Lake Constance in Germany, May 29-June 3, 2016. The International Conference on the Fundamentals of Adsorption (FOA) is the premier international conference in the field of Adsorption. The conference is held every 3 years under the auspices of the International Adsorption Society (IAS). FOA12 was chaired by Andreas Seidel-Morgenstern (Max Planck Institute and Otto von Guericke University, Magdeburg, Germany) and co-chaired by Alexander Neimark (Rutgers University, USA) and Paul Webley (University of Melbourne, Australia). Conference management services was provided by DECHEMA (Frankfurt, Germany) under the leadership of Andrea Köhl and Nina Weingärtner.

This conference series was initiated by Alan Myers and Georges Belfort in 1983. The previous locations and conference chairs were:

- FOA1, 1983, May 6-11, Schloss Elmau, GERMANY, A. L. Myers and G. Belfort

- FOA2, 1986, May 4-9, Santa Barbara, CA, USA, A. I. Liapis

- FOA3, 1989, May 5-9, Sonthofen, GERMANY, A. Mersmann

- FOA4, 1992, May 17-22, Kyoto, JAPAN, M. Suzuki

Andreas Seidel-Morgenstern

seidel-morgenstern@mpi-magdeburg.mpg.de

1 Max Planck Institute for Dynamics of Complex Technical System and Otto von Guericke University, Magdeburg, Germany
- FOA5, 1995, May 13-18, Pacific Grove, CA, USA, M. D. LeVan

- FOA6, 1998, May 23-27, Presquile de Giens, FRANCE, F. Meunier

- FOA7, 2001, May 20-25 Nagasaki, JAPAN, K. Kaneko

- FOA8, 2004, May 23-28, Sedona, AZ, USA, O. Talu

- FOA9, 2007, May 20-25, Giardini Naxos, Sicily, ITALY, M. Mazzotti

- FOA10, 2010, May 23-28, Awaji, JAPAN, M. Miyahara

- FOA11, 2013, May 19-24, Baltimore, MD, USA, P. A. Monson

A hallmark of the FOA conferences is a comprehensive coverage of the full spectrum of fundamental research and applications of adsorption. Topics covered at FOA12 included:

- Fundamentals of adsorption thermodynamics and kinetics.

- Molecular modeling of adsorption phenomena.

- Adsorbent materials.

- Characterization of adsorbent materials.

- Liquid phase and gas phase adsorption fundamentals.

- Multicolumn processes (SMB, PSA).

- Biotechnology applications of adsorption.

- Energy related applications.

- Environmental applications.

FOA12 was attended by 319 delegates from 32 countries throughout the World (Fig. 1). There were 313 technical presentations including three invited keynote lectures given by Peter Monson (University of Massachusetts, Amherst, USA), Ryong Ryoo (KAIST, Daejeon, ROK) and Dorota Antos (Rzeszow University of Technology, Poland), 12 


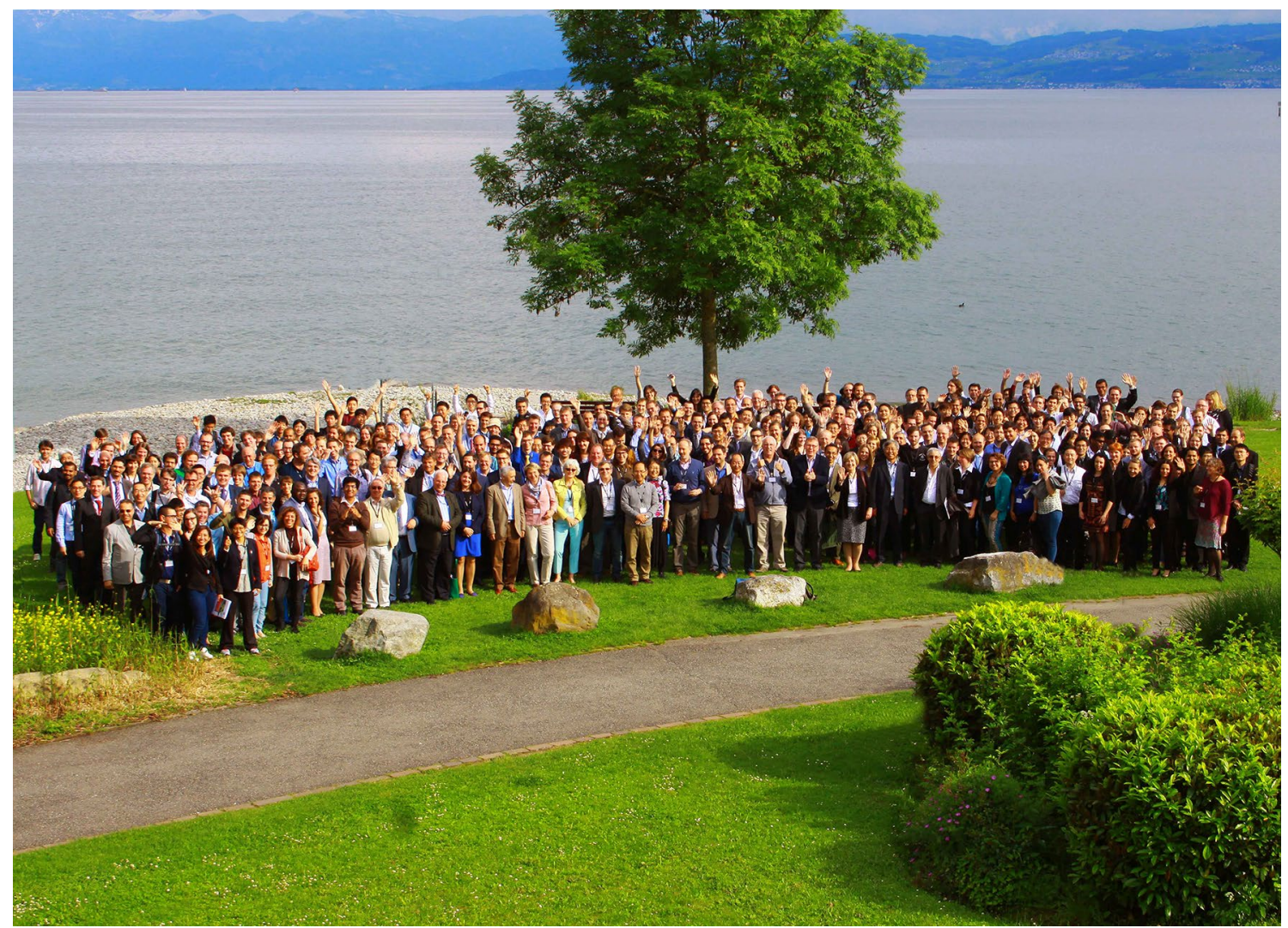

Fig. 1 Conference photograph from FOA12 at the shore of Lake Constance in Friedrichshafen, Germany. Just behind the second stone from the right are seen the Chairmen of FOA10, FOA11 and FOA12,

plenary lectures, 6 industry plenary lectures, 126 lectures in parallel sessions and 166 posters.

A new element for the FOA conference series was the organization of the following four very well attended workshops organized by leaders in their specific fields:

- Porous materials zoology: a dive into the world of COFs, CTFs, KITs, MAFs, MOFs, PIZOFs, ZIFs (Stefan Kaskel, TU Dresden, Germany)

- Recent advances in statistical thermodynamics and molecular simulation of Adsorption (Alex Neimark, Rutgers University, USA)

- Adsorption processes (Arvind Rajendran, University of Alberta, Canada, and Farooq Shamsuzzaman, National University of Singapore)

- Structural characterization of nanoporous materials by physical adsorption (Matthias Thommes, Quantachrome Corporation, USA)

Besides the scientific program FOA12 had more highlights. The Opening Lecture by Helmut Maier (University Bochum, Germany) "Important for the War: Chemists during the Third Reich" provided specific insight into a dark
Minoru Miyahara, Peter Monson and Andreas Seidel-Morgenstern (from left to right)

time and triggered numerous discussions, reflecting also the current political situation. More relaxing facets were the traditional "Japanese Night" and the excursion to the beautifully located Castle Neuschwanstein. The conference dinner in the Dornier Museum allowed becoming acquainted with a more specific past, namely the history of the Zeppelin airships and early airplanes, which originated from Friedrichshafen. It was a great pleasure for the participants to welcome Alfons Mersmann (formerly TU Munich, Germany), Chairman of FOA3 in 1989, and his wife Marlies at the conference dinner. During this event several awards were announced and new IAS fellows and directors were introduced.

FOA12 was supported financially by the following corporations and supporters:

- Knauer Wissenschaftliche Gerätebau GmbH, Berlin, Germany

- Microtrac BEL Corp., Osaka, Japan,

- Rubotherm GmbH, Bochum, Germany

- CarboTech AC, Essen, Germany

- Evonik Technology \& Infrastructure GmbH, Hanau, Germany 
- Hiden Isochema, Warrington,UK

- LEWA GmbH, Leonberg, Germany

- Micromeretics, GmbH, Aachen, Germany

- National Science Foundation, USA

- Fonds der Chemischen Industrie, Germany

- Quantachrome Instruments, USA

- Exxon Mobil, USA

The conference organizers and IAS are very grateful for the generous support of these companies and institutions, which made it possible, for example, to subsidize the travel costs of a group of young researchers who attended the conference.

The conference chairman is grateful to many individuals who helped make the organization and the conference itself such a success. The two conference co-chairs, Alex Neimark and Paul Webley, provided strong support in organizing the judging of the poster competition and coedited this special issue of "Adsorption". The members of the scientific advisory board and officers of IAS provided invaluable help with the review of the abstracts submitted. The German Local Organizing Team did an excellent and efficient job, which is gratefully acknowledged. Our special thanks to Christian Voss (Linde AG, Pullach, Germany) who organized a very interesting "Industrial Session". Finally should be mentioned, that the DECHEMA team and Stefanie Geyer from the Max Planck Institute in Magdeburg provided, together with the excellent staff of Graf-Zeppelin-Haus, truly outstanding conference management services, from the earlies planning stages through to the running of the event itself.

The papers in this special issue of Adsorption were treated as regular articles published in the journal and subjected to the standard peer review process. The editors greatly appreciate the efforts of the authors who contributed to this issue in a timely way and to the many individuals who served as reviewers. Alex, Paul and I are grateful to Gino Baron and Farooq Shamsuzzaman, the former and current Editor-in-Chief of Adsorption, for their support and guidance.

FOA13, to be chaired by Paul Webley will be held in Cairns, Australia, in 2019. The international adsorption community looks much forward to this next meeting of the FOA series. 